\title{
Evaluation of the repair capacities and color stabilities of a resin nanoceramic and hybrid CAD/CAM blocks
}

\author{
Hasibe Sevilay Bahadır'*, Yusuf Bayraktar² \\ 'Department of Restorative Dentistry, Faculty of Dentistry, Yıldırım Beyazıt University, Ankara, Turkey \\ ${ }^{2}$ Department of Restorative Dentistry, Faculty of Dentistry, Kırıkkale University, Kırıkkale, Turkey
}

\begin{abstract}
PURPOSE. This study evaluated the color stabilities of two computer-aided design and computer-aided manufacturing (CAD/CAM) blocks and a nanofill composite resin and the microtensile bond strength $(\mu \mathrm{TBS})$ between the materials. MATERIALS AND METHODS. Twelve specimens of $4 \mathrm{~mm}$ height were prepared for both Lava Ultimate (L) and Vita Enamic (E) CAD/CAM blocks. Half of the specimens were thermocycled (10,000 cycle, $5^{\circ}$ to $55^{\circ} \mathrm{C}$ ) for each material. Both thermocycled and non-thermocycled specimens were surface treated with one of the three different methods (Er,Cr:YSGG laser, bur, or control). For each surface treatment group, one of the thermocycled and one of non-thermocycled specimens were restored using silane (Ceramic Primer II), universal adhesive (Single Bond Universal), and nanofill composite resin of 4-mm height (Filtek Ultimate). The other specimens were restored with the same procedure without using silane. For each group, $1 \times 1 \times 8 \mathrm{~mm}$ bar specimens were prepared using a microcutting device. Bar specimens were thermocycled $\left(10,000\right.$ cycle, $5^{\circ}$ to $55^{\circ} \mathrm{C}$ ) and microtensile tests were performed. Staining of the materials in coffee solution was also compared using a spectrophotometer. Data were analyzed using one-way ANOVA, t-test and post-hoc Scheffe tests.

RESULTS. $\mu$ TBS were found similar between the thermocycled and non-thermocycled groups $(P>.05)$. The highest $\mu$ TBS (20.818 MPa) was found in the non-thermocycled, bur-ground, silane-applied E group. Silane increased $\mu$ TBS at some $E$ groups $(P<.05)$. Composite resin specimens showed more staining than CAD/CAM blocks $(P<.05)$. CONCLUSION. CAD/CAM blocks can be repaired with composite resins after proper surface treatments. Using silane is recommended in repair process. Color differences may be shown between CAD/CAM blocks and the nanofill composite after a certain time period. [J Adv Prosthodont 2020;12:140-9]
\end{abstract}

KEYWORDS: Computer-aided design and computer-aided manufacturing (CAD/CAM); Color stability; Er,Cr:YSGG laser; Microtensile bond strength; Thermal cycle

\section{INTRODUCTION}

Tooth-colored and metal-free indirect restorations are

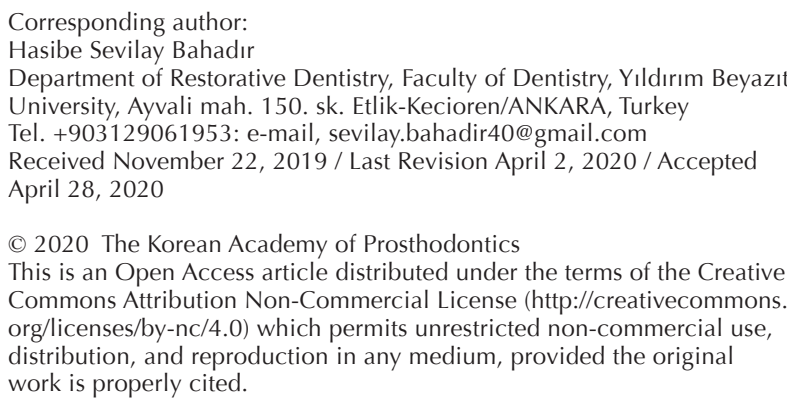

This study was funded by Kırıkkale University Scientific Research Projects Coordination Unit (Project No. 2018-012). increasingly preferred by patients in restorative dentistry. These restorations are esthetically pleasing and have some advantages over tooth-colored direct restorations, such as improved physical properties, resistance to wear and coloration, better contouring of proximal surfaces, reduced polymerization stress, residual monomer and biocompatibility. ${ }^{1}$ Resin-ceramic computer-aided design and computeraided manufacturing (CAD/CAM) blocks, with their resin and ceramic combined structures, are widely used in restorative dentistry due to their advantages over glass-ceramic blocks. The advantages of resin-ceramic blocks over glassceramic blocks are their flexural strength against brittleness, ${ }^{2}$ easier milling, ${ }^{3}$ increased marginal adaptation, ${ }^{4}$ and better repair capacity..$^{5}$ As examples of these blocks, Vita Enamic (Vita Zahnfabrik, Bad Säckingen, Germany) is a resin-infused hybrid ceramic block, and Lava Ultimate (3M ESPE, St. 
Paul, MN, USA) is a nanoceramic-filled resin block called "resin nanoceramic". Lava Ultimate is a resin structure containing silica nanoparticles with diameters of $20 \mathrm{~nm}$ and zirconia nanoparticles with $4-11 \mathrm{~nm}$ diameters. These nanoparticles constitute approximately $80 \%$ of the structure by weight. The organic polymer matrix of the material contains urethane dimethacrylate (UDMA) and bisphenol-A polyethylene glycol diether dimethacrylate (Bis-EMA) 20\% by weight. ${ }^{78}$ Vita Enamic typically consists of a polymerinfiltrated ceramic network. While the leucite-based, zirconia reinforced ceramic network constitutes $86 \%$ by weight and $75 \%$ by volume of the structure, the polymer-based network constitutes $25 \%$ by weight and $14 \%$ by volume. The specific composition of the ceramic is $\mathrm{SiO}_{2}, \mathrm{Al}_{2} \mathrm{O}_{3}$, $\mathrm{Na}_{2} \mathrm{O}, \mathrm{K}_{2} \mathrm{O}, \mathrm{B}_{2} \mathrm{O}_{3}, \mathrm{Zr}_{2} \mathrm{O}$, and $\mathrm{CaO}$. The polymer network consists of UDMA and triethylene glycol dimethacrylate (TEGDMA). ${ }^{8,9}$

Fractures may occur due to internal stress, parafunctional habits, degradation, design features, trauma, and so on in CAD/CAM and all dental restorations. ${ }^{8}$ Repairing the fractured site is often more advantageous than replacing the restoration completely. With the development of adhesive systems, restoration repair has become an important part of minimally invasive dentistry. Repairing CAD/CAM restorations is also important for preserving the remaining tooth tissue. It is an important disadvantage that replacing a repairable restoration accelerates the restoration cycle or leads to premature tooth loss. While replacing the restoration, cutting sound tooth tissue always causes irreversible damage and increases cavity size. ${ }^{10}$ Repair process should be evaluated according to the case and it is important to make the appropriate decision for restoration repair. There are many advantages to properly repairing a fractured restoration. Repairing procedure protects against the removal of sound tissue and increases survival rate of the restoration. The repair process of CAD/CAM restorations is more cost effective and represents a faster solution due to elimination of the laboratory procedures. ${ }^{10,11}$

Various procedures have been described in the literature to increase the repair bond strength, such as mechanical (etching with hydrofluoric acid, sandblasting, roughening with diamond burs, roughening with Er,Cr:YSGG laser) and chemical surface treatments (silane application). ${ }^{12}$ Along different surface treatment procedures, the aging of the material may also have an effect on repair capacity. To simulate the aging process, water storage and thermocycling have been used in various studies. ${ }^{13-15}$ Thermocycling is an effective procedure for aging dental materials that affects the physical properties and repair bond strength of the dental materials. ${ }^{16,17}$ In an esteemed study, it has been reported that 10,000 thermal cycles can correspond to 1 year. ${ }^{18}$ Thermocycling process adversely affects the physicochemical properties and the number of unreacted double bonds decreases on the surface of the composite structure. This reduces the repair bond strength of the composite material. ${ }^{16,19}$ However, the repair bond strength of resin containing CAD/CAM blocks prepared by polymerizing under high temperature and pressure has not yet been investigated.

Another side effect of the repair procedure is the possible color difference between the repaired material and the repair composite that may occur in the coming years. This should also be considered in repair protocols.

The aim of this study is to evaluate the $\mu$ TBS of two different CAD/CAM blocks with a nanofill composite resin. While half the specimens were thermocycled, the other half were not. Silane's effects on $\mu$ TBS and the color stability of the materials were also evaluated. The tested hypotheses are as follows:

- $\mathrm{H}_{1}$ : There are no significant differences in the repair capacities of CAD/CAM blocks after 10,000 thermal cycles;

- $\mathrm{H}_{2}$ : Silane application and different surface treatment procedures affect $\mu \mathrm{TBS}$; and

- $\mathrm{H}_{3}$ : Color differences occur between CAD/CAM blocks and repair composite resin in a short time.

\section{MATERIALS AND METHODS}

Two different CAD/CAM restorative materials, Lava Ultimate (3M ESPE, St. Paul, MN, USA) and Vita Enamic (VITA Zahnfabrik, Bad Säckingen, Germany), were used in the study. The manufacturers and material compositions are given in Table 1.

Twenty-four specimens of 4-mm height were prepared using Lava Ultimate $\left(\mathrm{n}_{\mathrm{L}}=12\right)$ and Vita Enamic $\left(\mathrm{n}_{\mathrm{E}}=12\right)$ CAD/CAM blocks. To obtain standard surfaces, the specimens were polished using 400-, 600-, 800-, and 1,200-grit silicon carbide papers each for $60 \mathrm{~s}$. Then, the specimens were cleaned by standing in distilled water for $5 \mathrm{~min}$. While half the specimens were thermocycled 10,000 times in water baths between $+5^{\circ} \mathrm{C}$ and $+55^{\circ} \mathrm{C}$ with a rest time of $20 \mathrm{~s}$ in each bath, the other half were not. Thermocycled specimens were tagged as " 1 " and the nonthermocycled specimens as "2." Following this, all the specimens were randomly divided into three subgroups for different surface treatments, as follows:

- Group A (control group): No treatment;

- Group B (diamond bur): The specimens were roughened with a green-banded diamond fissure bur (Meisinger, Neuss, Germany) with a $107-181-\mu \mathrm{m}$ grain size using a high-speed rotary tool under water cooling for $4 \mathrm{~s}$. The bur was changed to a new one after every 5 specimens; and

- Group C (Er,Cr:YSGG laser): The specimens were roughened with an Er,Cr:YSGG laser (Waterlase, Biolase Technology, San Clemente, CA, USA) with a wavelength of $2780 \mathrm{~nm}$. The specimens were applied with a $600-\mu \mathrm{m}$ diameter fiber tip at a distance of $1 \mathrm{~mm}$ and sweeping for $20 \mathrm{~s}$. The parameters used during laser application were $3 \mathrm{~W}, 20 \mathrm{~Hz}$, air level $60 \%$, and water level $50 \%$.

After the surface treatments were applied, all the samples were washed with distilled water and dried with oil-free air spray. Then, all the groups were divided further into two subgroups, and GC Ceramic Primer II (GC, Tokyo, Japan) was applied as a thin layer with a small-tipped applicator for 
Table 1. Manufacturers and the compositions of materials used

\begin{tabular}{|c|c|c|c|}
\hline Material & Manufacturer & Composition & Lot number \\
\hline Lava Ultimate CAD/CAM Block & 3M ESPE, St. Paul, MN, USA & $80 \%$ wt nanoceramic, $20 \%$ wt resin (UDMA, Bis-EMA) & N550735 \\
\hline Vita Enamic CAD/CAM Block & $\begin{array}{l}\text { Vita Zahnfabrik, } \\
\text { Bad Säckingen, Germany }\end{array}$ & $\begin{array}{l}86 \% \text { wt feldspaa ceramic, } 14 \% \text { wt polymer (UDMA, } \\
\text { TEGDMA) }\end{array}$ & 60250 \\
\hline $\begin{array}{l}\text { Filtek Ultimate Composite Resin } \\
\text { (A2 Body) }\end{array}$ & $\begin{array}{l}\text { 3M ESPE, St. Paul, } \\
\text { MN, USA }\end{array}$ & $\begin{array}{l}\text { Bis-GMA, UDMA, TEGDMA, Bis-EMA, } 20 \mathrm{~nm} \text { silica and } 4 \text { - } \\
11 \mathrm{~nm} \text { zirconia filler, camphorquinone, accelerators, } \\
\text { pigments and others. }\end{array}$ & N841976 \\
\hline Single Bond Universal & $\begin{array}{l}\text { 3M ESPE, St. Paul, } \\
\text { MN, USA }\end{array}$ & $\begin{array}{l}\text { MDP monomer, dimethacrylate resins, HEMA, } \\
\text { Vitrebond }{ }^{\mathrm{TM}} \text { copolymer, filler, ethanol, water, initiators and } \\
\text { silane }\end{array}$ & 665259 \\
\hline Ceramic Primer II & GC, Tokyo, Japan & $\begin{array}{l}90-<100 \% \text { ethyl alcohol, } 1-2,5 \% \text { MDP, } 1 \text { - 2,5\% } 2.2 \\
\text { 'Ethylene dioxyethyl dimethacrylate, } \\
0,5-1 \% \text { (1-methyl Ethylidene) bis [4,1-phenylenoxy } \\
\text { (2-hydroxy-3,1-propanedyl)] bis methactylatelate }\end{array}$ & 1608041 \\
\hline Coarse Fissure Bur & Meisinger, Neuss, Germany & $107-181 \mu \mathrm{m}$ grain size, diamond fissure bur & Q56782 \\
\hline MZ6 Laser Tip & $\begin{array}{l}\text { BioLase Technology, } \\
\text { CA, USA }\end{array}$ & $600 \mu \mathrm{m}$ diameter, fiber laser tip & 4003138 \\
\hline OptiDisk & Kerr, CA, USA & $\begin{array}{l}\text { Polyester containing aluminum oxide particles, translucent } \\
\text { polishing discs, three-stage polishing system }\end{array}$ & 4655466 \\
\hline
\end{tabular}

Abbreviations: Bis-GMA: bisphenol A glycol dimethacrylate, UDMA: urethane dimethacrylate, Bis-EMA: bisphenol A ethoxylated dimethacrylate, TEGDMA: triethylene glycol dimethacrylate, HEMA: 2 hydroxyethyl methacrylate, MDP: methacryloyloxydecyl dihydrogen phosphate

$60 \mathrm{~s}$ and dried with an oil-free air spray to one of the subgroups randomly. The silane primer applied groups were tagged "+ S". Then, Single Bond Universal (3M ESPE, St. Paul, MN, USA) was applied to all the specimens for $20 \mathrm{~s}$, thinned with mild air for $5 \mathrm{~s}$, and polymerized with an LED curing device (Elipar S10, 3M ESPE, St. Paul, MN, USA) for $10 \mathrm{~s}$. After the bonding process, specimens were placed in specially prepared stainless-steel molds, and Filtek Ultimate composite resin (3M ESPE, St. Paul, MN, USA) was placed at a thickness of $2 \mathrm{~mm}$ and polymerized with Elipar S10 for $20 \mathrm{~s}$. The composite resin was totally restored to $4 \mathrm{~mm}$ in height. After the final layer of the composite resin was placed, it was covered with a Mylar strip to remove the oxygen inhibition layer. After the specimens were removed from the molds, they were polished with aluminum oxidecoated flexible polishing discs (OptiDisc, Kerr, Orange, CA, USA). Specimens of $1 \times 1 \times 8 \mathrm{~mm}$ in size were prepared by sectioning ceramic-resin blocks longitudinally with a lowspeed cutting device (Microcut 201, Metkon, Bursa, Turkey). At least 23 sticks were obtained from each group. Following this, the sticks were thermocycled for 10,000 cycles between $+5^{\circ} \mathrm{C}$ and $+55^{\circ} \mathrm{C}$, with a rest time of $20 \mathrm{~s}$ in each bath. The study design and grouping of the specimens are shown in Figure 1.

For performing $\mu$ TBS test, the specimens were put into a universal testing machine (Microtensile Tester, Bisco Inc., Schaumburg, IL, USA). Sticks placed on the device were fixed with cyanoacrylate-based adhesive at both ends, and care was taken to avoid putting the adhesive on bonding surfaces. The sticks were subjected to a tensile force of 0.5 $\mathrm{N}$ at a speed of $1 \mathrm{~mm} / \mathrm{min}$. Microtensile bond strength values were measured, and the force unit was determined in Newton $(\mathrm{N})$. Then, these values $(\mathrm{N})$ were converted to $\mathrm{MPa}$ for each sample according to following formula: $\mathrm{MPa}=$ force / area $\left(\mathrm{N} / \mathrm{mm}^{2}\right)$. The split surfaces of sticks were examined by stereomicroscope (S100 OPMI pico, Carl Zeiss MeditecAG, Yena, Germany) to determine the type of fracture. The fracture types are classified as follows:

- Type I: Adhesive fracture between the ceramic and composite;

- Type II: Cohesive fracture in the ceramic or composite; and

- Type III: Mixed fracture between the ceramic and composite, with more than half the composite on the ceramic surface.

To determine the surface roughness of materials, twelve specimens were prepared with a $1.2-\mathrm{mm}$ height for each surface treatment procedure of each material $\left(n_{\text {total }}=72\right)$. After applying the same surface treatment procedures, the specimens were washed with distilled water and dried with oil-free air spray. Roughness values were measured using a profilometer (Perthometer M2, MAHR GmbH, Göttingen, Germany) and average roughness values $\left(\mathrm{R}_{\mathrm{a}}\right)$ were recorded. The profilometer was calibrated for each measurement. The surfaces of the specimens were also evaluated using atomic force microscopy (AFM; Veeco MultiMode V, Santa Barbara, CA, USA). An NP-type V-shaped Si3N4 tip (Santa Barbara, CA, USA) with a radius of $100 \mathrm{~nm}$ was used. Surface mea- 
surements were performed at a scanning speed of $2.03 \mathrm{~Hz}$, and $20 \times 20 \mu \mathrm{m}$ areas were scanned. Three-dimensional images with $256 \times 256$-pixel resolution were recorded. AFM images from the specimens were obtained in tapping mode. The calibration was repeated at each measurement stage. The same specimens were coated with palladium and examined using scanning electron microscopy (SEM; JEOL JSM-5600, Tokyo, Japan). For standardization, SEM images were taken at $\times 1,000$ magnification.

For color measurement, a total of 72 specimens $(2 \mathrm{~mm}$ thick) were obtained from each of the Vita Enamic ( $\mathrm{n}=$ 24), Lava Ultimate $(n=24)$, and composite resin $(n=24)$ materials. Then, all the specimens were thermocycled for 10,000 cycles between $+5^{\circ} \mathrm{C}$ and $+55^{\circ} \mathrm{C}$ with a rest time of $20 \mathrm{~s}$ in each bath. After the thermocycling procedure, the initial color values of all the specimens were determined using a spectrophotometer (VITA Easyshade Compact, Vident, Germany). The device was calibrated before each measurement. Each measurement was performed on a standard white background to eliminate the background effect, at the same time of the day. During the measurements, the fiber optic tip of the device was placed perpendicular to the specimens and parallelized to the ground. Color measurements were performed three times for each specimen. After the initial color values were determined, half of all the specimens were immersed in distilled water and half in coffee solution. Two grams of Nescafe powder (Nestle, Vevey, Switzerland) and $200 \mathrm{~mL}$ of hot water were used in the preparation of the coffee. The solutions were renewed every day. Color measurements were determined on the $1 \mathrm{st}$, 7 th, 14th, and 28th days. The color change in the specimens was formulated with the $\Delta \mathrm{E}$ parameter calculated with $\mathrm{L}, \mathrm{a}$, and $b$ value:

$$
\Delta \mathrm{E}=\left[\left(\Delta \mathrm{L}_{0}-\Delta \mathrm{L}_{1}\right)^{2}+\left(\Delta \mathrm{a}_{0}-\Delta \mathrm{a}_{1}\right)^{2}+\left(\Delta \mathrm{b}_{0}-\Delta \mathrm{b}_{1}\right)^{2}\right]^{1 / 2}
$$

Table 2. The mean $\mu$ TBS (MPa), standard deviation (SD) and statistical results of $\mathrm{E}$ group specimens

\begin{tabular}{lccc}
\hline Eb2 $+S(n=36)$ & $20.818 \pm 6.266$ & A \\
Ec2 $+S(n=30)$ & $14.811 \pm 4.372$ & $B$ \\
Ec1 $\quad(n=39)$ & $14.632 \pm 15.281$ & B \\
Ea1 $+S(n=40)$ & $13.255 \pm 5.969$ & BC \\
$E b 1+S(n=26)$ & $11.878 \pm 4.987$ & BCE \\
Ec1 $+S(n=27)$ & $11.578 \pm 5.184$ & BCFG \\
Ea2 $+S(n=27)$ & $11.115 \pm 6.159$ & BCFG \\
Ec2 $\quad(n=30)$ & $9.539 \pm 4.122$ & BCFG \\
Ea2 $\quad(n=30)$ & $8.389 \pm 4.214$ & CH \\
Eb2 $\quad(n=25)$ & $6.817 \pm 2.863$ & EGH \\
Ea1 $\quad(n=23)$ & $6.475 \pm 5.66$ & EGH \\
Eb1 $\quad(n=32)$ & $5.775 \pm 3.908$ & $F H$ \\
\hline
\end{tabular}

Different letters indicate significant differences $(P<.05)$.
The data of the microtensile test and surface roughness were analyzed using SPSS v22.0 program. Differences between the two groups were analyzed using the independent group t-test. The one-way analysis of variance (ANOVA) test was used for comparing quantitative continuous data among more than two independent groups. The complementary post hoc Scheffe test was used to determine the differences after the ANOVA test. In the evaluation of color measurements, the mean and standard deviation were used as the descriptive statistical method. In determining the difference between intragroup repeated measurements, the repeatedmeasures ANOVA test was used. Differences among more than two groups were analyzed by the one-way ANOVA test and post hoc Bonferroni test.

\section{RESULTS}

According to the $\mu$ TBS test results of the specimens, it was found that the non-thermocycled, bur-ground, and silaneapplied E group (Eb2 $+\mathrm{S}$ group, $\mu \mathrm{TBS}=20.818 \pm 6.266$ $\mathrm{MPa})$ showed a significantly higher bond strength than the other groups $(P<.05)$. The group with the lowest bond strength was found to be the thermocycled, bur-ground, and non-silane-applied E group (Eb1 group, $\mu$ TBS $=5.775$ $\pm 3.908 \mathrm{MPa})$. It was found that the silane application significantly increased the bond strength in some $\mathrm{E}$ groups $(\mathrm{Eb} 1+\mathrm{S}, \mathrm{Eb} 2+\mathrm{S}, \mathrm{Ea} 1+\mathrm{S}$ groups; $P<.05)$. In the other groups, it was observed that silane application did not cause a significant increase in bond strength. Thermocycling 10,000 times did not affect the $\mu$ TBS except that of the $\mathrm{Eb} 1 / 2+\mathrm{S}$ groups $(\mathrm{Eb} 2+\mathrm{S}>\mathrm{Eb} 1+\mathrm{S})$. The microtensile bond strength results of Vita Enamic and Lava Ultimate materials are shown in Table 2 and Table 3.

According to the $\mu$ TBS results of the specimens prepared from the Lava Ultimate CAD/CAM block, it was

Table 3. The mean $\mu$ TBS (MPa), standard deviation (SD) and statistical results of $L$ group specimens

\begin{tabular}{|c|c|c|}
\hline $\mathrm{Lb} 2+\mathrm{S}(\mathrm{n}=25)$ & $14.661 \pm 6.796$ & $A$ \\
\hline Lb2 $\quad(n=34)$ & $14.561 \pm 7.719$ & $A$ \\
\hline$L b 1+S(n=27)$ & $13.381 \pm 12.044$ & $\mathrm{AC}$ \\
\hline$L c 1+S(n=26)$ & $12.196 \pm 5.715$ & $\mathrm{ABC}$ \\
\hline$L a 1+S(n=36)$ & $11.745 \pm 8.577$ & $\mathrm{ABC}$ \\
\hline Lb1 $\quad(n=38)$ & $11.030 \pm 4.577$ & $\mathrm{ABC}$ \\
\hline Lc2 $\quad(n=30)$ & $10.195 \pm 4.67$ & $\mathrm{ABC}$ \\
\hline $\mathrm{Lc} 2+\mathrm{S}(\mathrm{n}=35)$ & $1.034 \pm 3.224$ & $\mathrm{ABC}$ \\
\hline$(n=29)$ & $7.978 \pm 2.977$ & $\mathrm{BC}$ \\
\hline $\mathrm{La} 2+\mathrm{S}(\mathrm{n}=27)$ & $7.578 \pm 2.031$ & $B$ \\
\hline La1 $\quad(n=28)$ & $7.524 \pm 5.957$ & $B$ \\
\hline La2 $\quad(n=27)$ & $7.226 \pm 5.161$ & $B$ \\
\hline
\end{tabular}

Different letters indicate significant differences $(P<.05)$. 
found that the Lb2 $+\mathrm{S}$ group $(\mu \mathrm{TBS}=14.661 \pm 6.796$ $\mathrm{MPa}$ ) showed a significantly higher bond strength than the other groups $(P<.05)$. The group with the lowest bond strength was the La2 group $(\mu \mathrm{TBS}=7.226 \pm 5.161 \mathrm{MPa})$. The bond strengths between the groups with and without silane treatment were similar $(P>.05)$. In addition, the bond strengths were similar between the thermocycled and non-thermocycled groups $(P>.05)$.

The bond strengths of the specimens prepared with Lava Ultimate, with and without thermocycling and burground $(\mathrm{Lb} 1=11.030 \pm 4.577 \mathrm{MPa}, \mathrm{Lb} 2=14.561 \pm 7.719$ $\mathrm{MPa}$ ), were found to be significantly higher than those of the specimens prepared with Vita Enamic with and without thermocycling and bur roughening $(\mathrm{Eb} 1=5.775 \pm 3.908$
$\mathrm{MPa}, \mathrm{Eb} 2=6.817 \pm 2.863 \mathrm{MPa} ; P<.05)$. The bond strength of the specimens prepared with Vita Enamic with thermal cycling and laser roughening $(\mathrm{Ec} 1=14.632 \pm$ 15.281 MPa) was found to be significantly higher than that of the specimens prepared with Lava Ultimate with thermocycling and laser roughening $(\mathrm{Lc} 1=7.978 \pm 2.977 \mathrm{MPa} ; P$ $<.05)$.

The $\mu$ TBS of non-thermocycled, bur-ground, and silane applied Vita Enamic specimens $(\mathrm{Eb} 2+\mathrm{S}=20.818 \pm 6.266$ $\mathrm{MPa}$ ) was significantly higher than the non-thermocycled, bur-ground, and silane applied Lava Ultimate specimens $(\mathrm{Lb} 2+\mathrm{S}=14.661 \pm 6.796 ; P<.05)$. The fracture types of the Vita Enamic and Lava Ultimate materials are shown in Fig. 1.

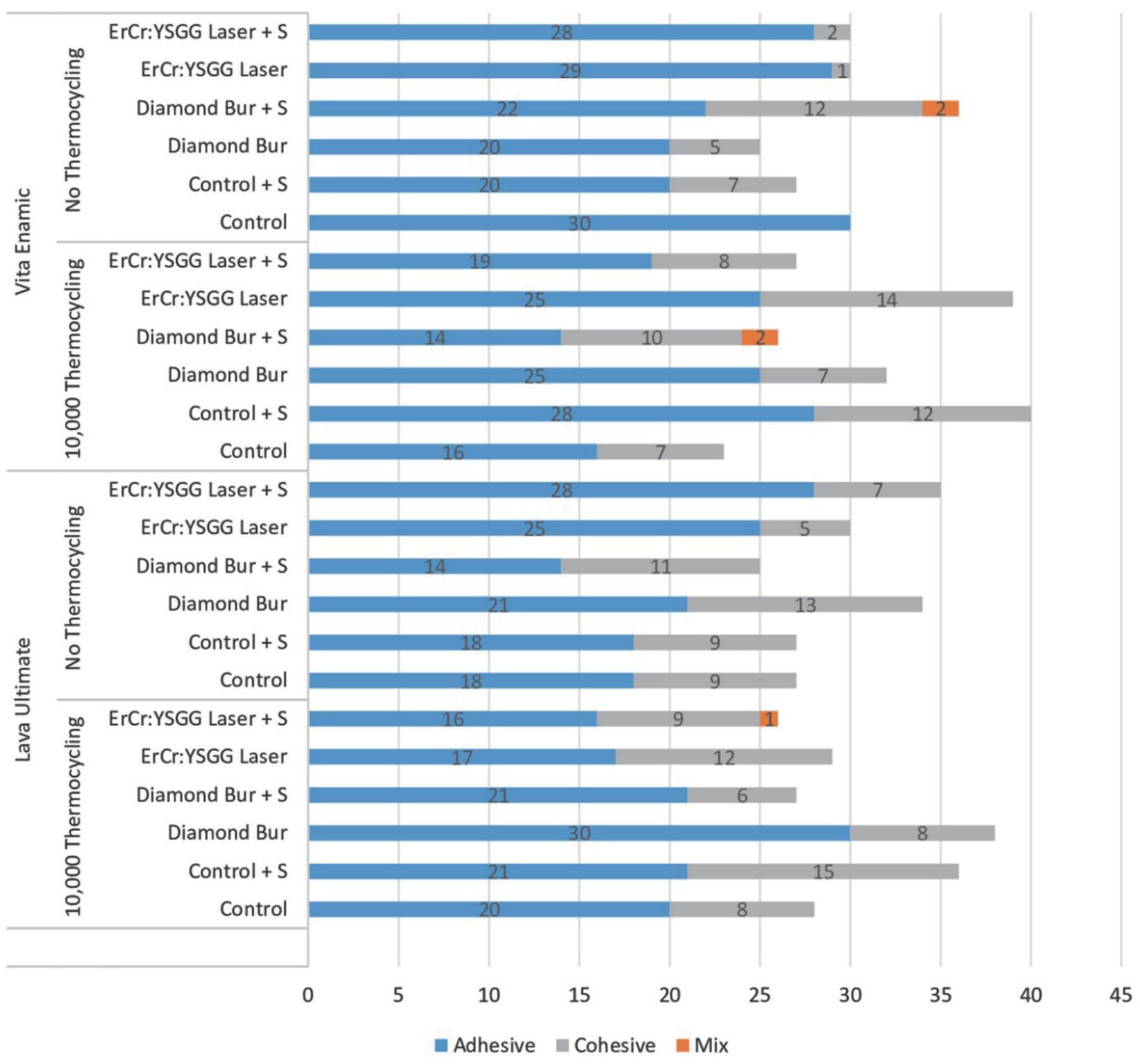

Fig. 1. The fracture types of the groups (Type 1: adhesive fracture, Type 2: cohesive fracture, Type 3: mixed fracture). 
According to the average roughness scores (Ra), lasertreated specimens showed the highest results $(\mathrm{Ec}=6.782 \pm$ $1.120 \mu \mathrm{m}, \mathrm{Lc}=6.915 \pm 0.958 \mu \mathrm{m} ; P<.05)$. The Ra scores of bur-ground specimens $(\mathrm{Eb}=2.292 \pm 0.966 \mu \mathrm{m}, \mathrm{Lb}=$ $2.529 \pm 0.911 \mu \mathrm{m})$ were found to be higher than those of the control groups $(\mathrm{Ea}=0.250 \pm 0.116 \mu \mathrm{m}, \mathrm{La}=0.360 \pm$ $0.243 \mu \mathrm{m} ; P<.05)$. According to the AFM evaluation, relatively flat surfaces were seen in the control groups, whereas small hills and grooves were observed in the bur-ground groups. The Er,Cr:YSGG laser-treated specimens could not be measured with AFM because of excessive roughness. The same specimens used in AFM evaluation were also evaluated using SEM, and similar grooves were seen, especially in the L group. The SEM images of the laser-treated surfaces showed more irregular and melt-like surfaces. The AFM and SEM images were found to be compatible with
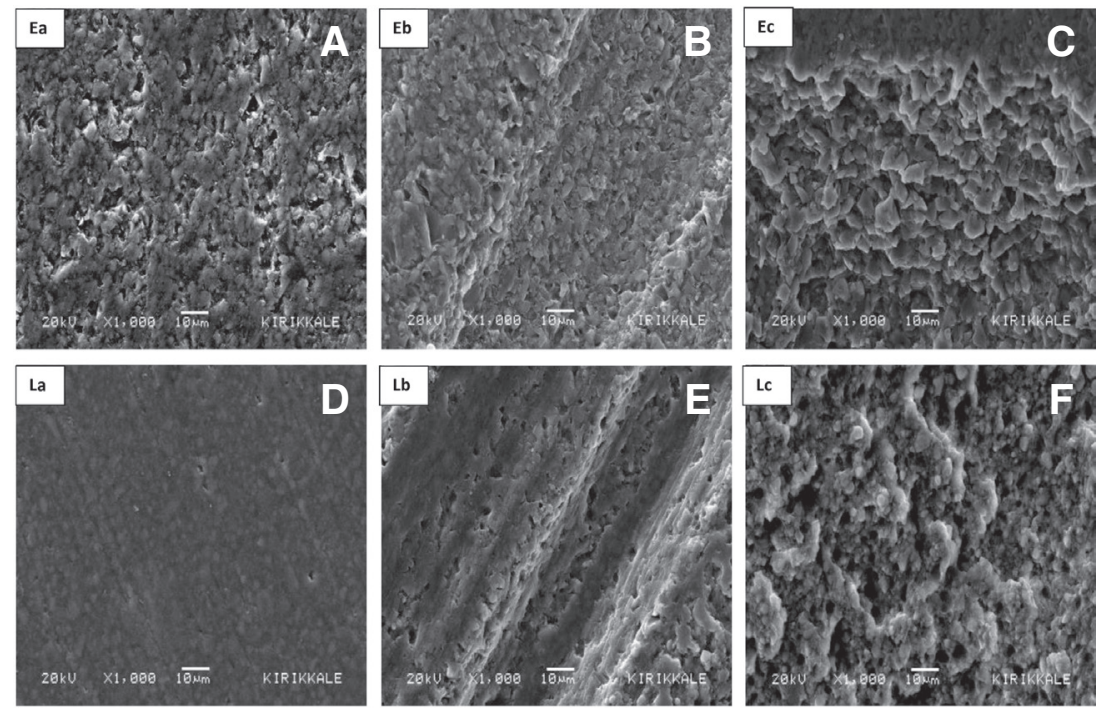

Fig. 2. SEM images of the groups. (A) Ea: Control group of Vita Enamic, (B) Eb: Bur-ground Vita Enamic group, (C) Ec: Laser-treated Vita Enamic group, (D) La: Control group of Lava Ultimate, (E) Lb: Bur-ground Lava Ultimate group, (F) Lc: Laser-treated Lava Ultimate group.

A
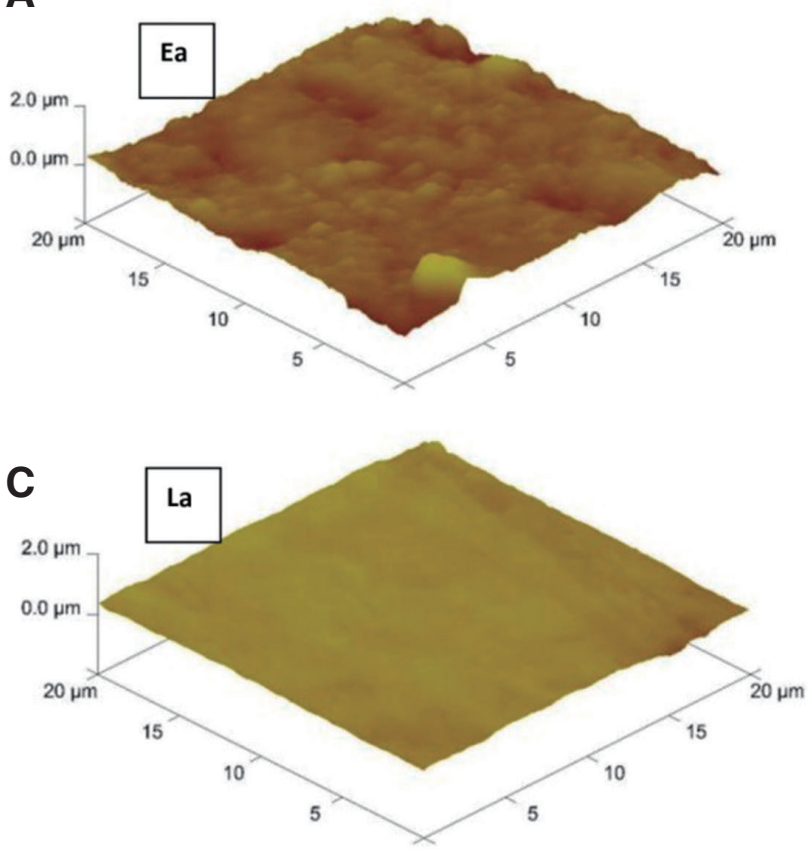
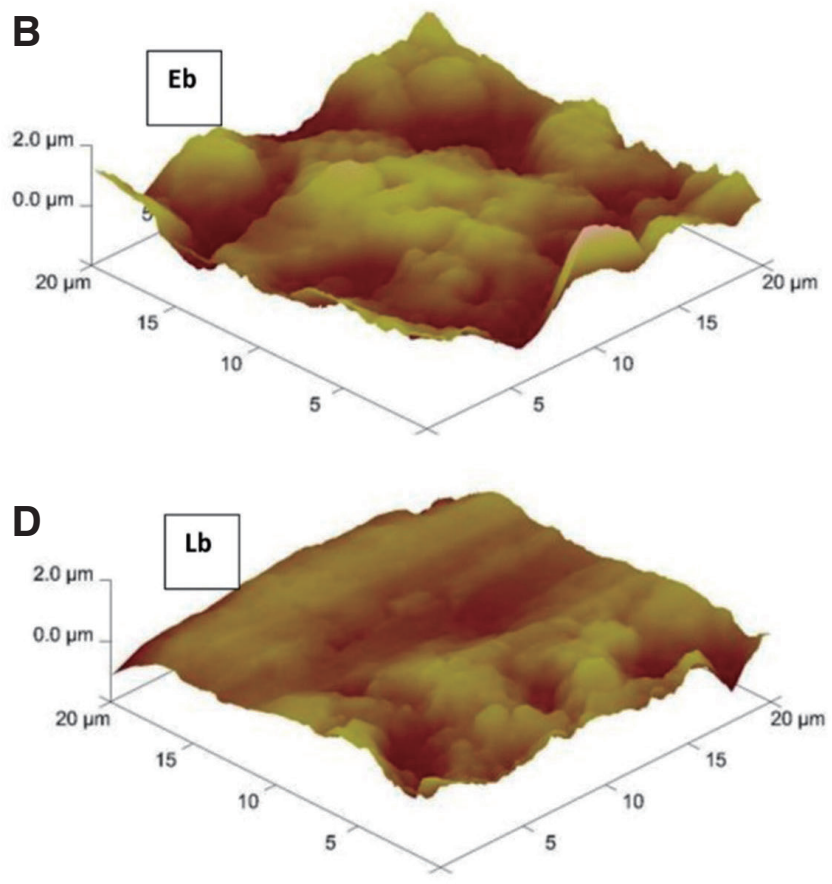

Fig. 3. AFM images of the groups. (A) Ea: Control group of Vita Enamic, (B) Eb: Bur-ground Vita Enamic group, (C) La: Control group of Lava Ultimate, (D) Lb: Bur-ground Lava Ultimate group. 
the profilometer results (Fig. 2 and Fig. 3).

The color change values of the composite specimens that were immersed in coffee solution were found to be higher than those of the other specimens after 24 hours $(P<.05)$. The composite resin specimens also showed more staining than the CAD/CAM blocks for both distilled water and coffee solution (after 7, 14, and 28 days; $P<.05$ ). The Lava Ultimate and Vita Enamic specimens that were immersed in distilled water showed similar color change values after 24 hours and 7, 15, and 28 days $(P>.05)$. Significant color changes were seen after 14 and 28 days between Lava Ultimate $\left(\Delta \mathrm{E}_{14}=4.975 \pm 1.027, \Delta \mathrm{E}_{28}=5.529 \pm 0.988\right.$ for Lava Ultimate) and Vita Enamic $\left(\Delta \mathrm{E}_{14}=3.570 \pm 1.805\right.$, $\Delta \mathrm{E}_{28}=3.774 \pm 1.754$ for Vita Enamic) specimens that were immersed in coffee solution $(P<.05)$ (Fig. 4).

\section{DISCUSSION}

This study evaluated the repair capacities of the resin nanoceramic (L) and hybrid (E) CAD/CAM blocks with and without a 10,000-thermocycle process. According to the findings of this study, the first null hypothesis was accepted, and it was found that 10,000 thermocycling of the materials did not affect the $\mu$ TBS. However, the second null hypothesis was partially accepted, and the third hypothesis was also accepted. While silane application caused high $\mu$ TBS values, especially in some E groups, no effect was observed in L group specimens. After a short time $(24 \mathrm{~h})$, evident color changes were detected between the composite specimens and CAD/CAM blocks.

The strong bond strength between CAD/CAM materials and composite resin improves the success of the repair process in clinical applications. Different surface treatments and chemical interactions are required to increase the bond strength. ${ }^{20}$ Er,Cr:YSGG laser with a wavelength of $2.78 \mu \mathrm{m}$ has been used for surface roughening of different CAD/ CAM materials in the literature. ${ }^{21-23}$ According to Kirmali et al., ${ }^{24}$ when roughening the composite surfaces with $1.5-\mathrm{W}$, 2-W, and 3-W Er,Cr:YSGG laser irradiation, rough and irregular surfaces occur and acceptable shear bond strength similar to sandblasting is obtained. Barutcigil et al..$^{23}$ also reported a mean SBS of $9.137 \mathrm{MPa}$ for Er,Cr:YSGG laserirradiated Vita Enamic specimens at $2 \mathrm{~W}$. According to the same study, this result was found to be similar to those obtained from CoJet sandblasting, $50-\mu \mathrm{m} \mathrm{Al}_{2} \mathrm{O}_{3}$ sandblasting, and $10 \% \mathrm{HF}$ acid etching surface treatments. According to the findings of this study, $3 \mathrm{~W} \mathrm{Er,Cr:YSGG} \mathrm{laser-treated}$ $\mathrm{L}$ and $\mathrm{E}$ surfaces showed acceptable $\mu \mathrm{TBS}$, and the scores were similar to those of various control and bur groups. After the surface roughening with the Er,Cr:YSGG laser, rough areas were formed on the surfaces of the specimens. The Er,Cr:YSGG laser can be considered as an alternative method to bur grinding and various surface treatment procedures, such as sandblasting and HF acid etching, for relatively soft materials like $\mathrm{L}$ and $\mathrm{E}$. According to the literature, Er,Cr:YSGG laser irradiation has shown conflicting

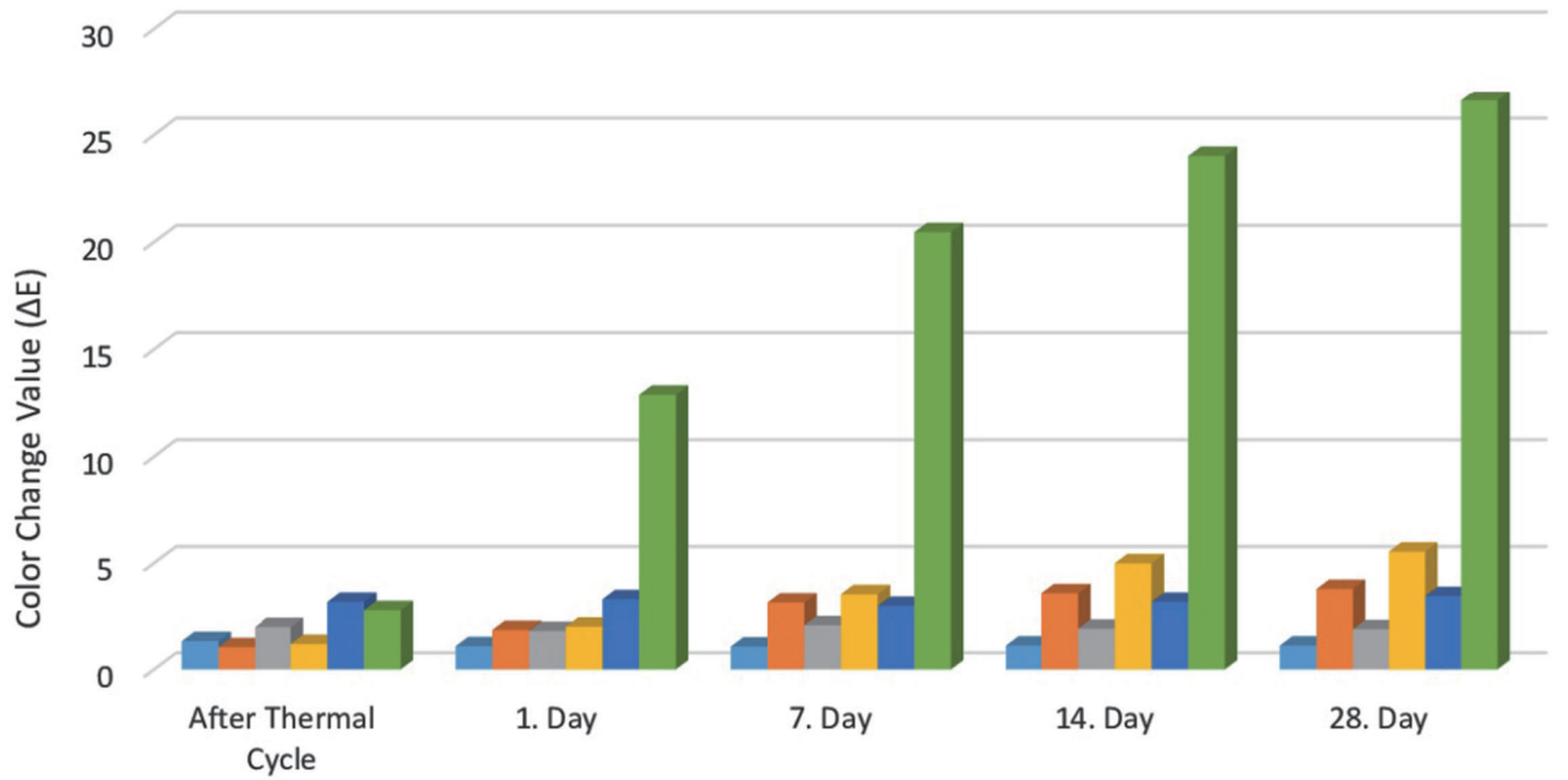

\section{चita Enamic in Distilled Water Vita Enamic in Coffee Solution n Lava Ultimate in Coffee Solution $\square$ Composite in Distilled Water}

Lava Ultimate in Distilled Water

n Composite in Coffee Solution

Fig. 4. The color change values $(\Delta \mathrm{E})$ of the groups. 
results with glass-ceramic materials. ${ }^{25-27}$

Thermocycling is defined as the process of mimicking the temperature changes to which restorations and teeth are exposed in the mouth. This method is frequently used in in vitro studies. ${ }^{28-30}$ Gale and Darvell ${ }^{18}$ stated that 10,000 cycles are equivalent to approximately 1 year of function in vivo. The repairing needs of restorations generally arise after a long process of months or years. Meanwhile, the restorations are exposed to the oral environment and many changes in this environment. This study investigated the repair capacity of CAD/CAM restorations performed using $\mathrm{L}$ and $\mathrm{E}$ after 10,000 thermocycles, and it was found that 10,000 thermocycles did not affect $\mu \mathrm{TBS}$, except in two cases $(\mathrm{Eb} 2$ $+\mathrm{S}>\mathrm{Eb} 1+\mathrm{S})$; this result is attributed to the silane effect. Silane was thought to have the best effect in the group with a uniform roughness and no thermocycling. Özel Bektaş et al..$^{29}$ reported that 10,000 thermocycles affected the repair bond strength for both Er:YAG laser and bur-treated composite resin specimens. According to the findings of this study, 10,000 thermocycles did not affect the repair capacity of the $\mathrm{E}$ and L CAD/CAM blocks. This result can be explained by the more stable structures of $\mathrm{E}$ and $\mathrm{L} \mathrm{CAD} /$ CAM blocks in relation to direct composite specimens. However, after increasing the number of thermocycles $(20,000,30,000$, etc.), the changes in the repair capacities of the mentioned CAD/CAM blocks is still a matter of concern. Yet, no study was found on the effect of an increasing number of thermocycles on the repair capacity of $\mathrm{E}$ and $\mathrm{L}$ CAD/CAM blocks. This topic can be considered in another study.

Silane coupling agents are used to improve the bond strength between certain dental restorative materials such as composite resins and ceramics by providing chemical bonding. These agents are organic silicates with bifunctional structures, in which one function is forming covalent bonds with inorganic structures and the other is forming covalent bonds with organic structures. ${ }^{31}$

According to the findings of this study, the $\mu$ TBS of the $\mathrm{L}$ specimens in both the silane-treated and non-silane-treated groups were similar. Although some of the L groups showed higher $\mu \mathrm{TBS}$, this was not significant. In contrast, silane application significantly increased the $\mu$ TBS in some $\mathrm{E}$ specimens $(\mathrm{EB} 1+\mathrm{S}, \mathrm{EB} 2+\mathrm{S}, \mathrm{EA} 1+\mathrm{S})$. This difference between $\mathrm{E}$ and $\mathrm{L}$ was related to the different microstructures and silica contents of the materials. These results are consistent with the studies of Elsaka ${ }^{32}$ and Demirtag and Culhaoglu, ${ }^{30}$ who evaluated the silane and surface treatment effects on the bond strength of $\mathrm{L}$ and $\mathrm{E}$.

Although a silane-containing universal bonding agent was used in this study, an additional silane application further increased the bond strength of some E specimens significantly and a certain amount for L specimens. According to the findings of this study and the literature, even if a universal adhesive system containing silane is used, it is advised to employ a silane coupling agent during repairing procedures of CAD/CAM blocks. This is because universal bonding agents are almost always more acidic (Single Bond
Universal, $\mathrm{pH}=2.7$ ) than silane coupling agents (Ceramic Primer II, $\mathrm{pH}=4.0)$; thus, silane in the adhesive can be continuously hydrolyzed and reacted during storage, and consequently, it can be inactivated. ${ }^{33}$ Murillo-Gómez et al. ${ }^{34}$ reported that the short and long-term bond strengths are better when silane and the adhesive system are applied separately.

While micro-bond strength tests cause better stress distribution at the adhesive interface and result in more adhesive fractures, macro-bond strength tests result in more cohesive fractures and overstatements of bond strengths. Micro-testing methods are commonly used for reducing flaws in the results of macro-testing methods. ${ }^{35,36}$ According to the findings of the present study, the $\mu \mathrm{TBS}$ test resulted in more adhesive fractures; this result was in accordance with the literature.

In this study, the color change values of the materials used in the repair process were also examined after immersion in coffee and distilled water. Specimens stored in distilled water were used as the control group. To perform an objective color evaluation, a spectrophotometric device was used in this study, allowing a quantitative color assessment. In the CIE $\mathrm{L} * \mathrm{a} * \mathrm{~b} *$ color system, the difference between two colors $(\Delta \mathrm{E})$ is expressed as the numerical value of the distance between the $\mathrm{L}^{*}, \mathrm{a} *, \mathrm{~b} *$ coordinates of these colors. ${ }^{37}$ In this study, the acceptability limit of $\Delta \mathrm{E}$ was determined as $3.5,{ }^{38}$ and it was seen that all the materials that were immersed in coffee showed time-dependent color changes. There was no discoloration above the limit value at the end of the 28th day in the specimens kept in distilled water. While the composite resin specimens immersed in coffee were discolored above the limit immediately after 1 day $(\Delta \mathrm{E}=12.870 \pm 4.520)$, the $\mathrm{L}$ and $\mathrm{E}$ specimens showed a discoloration above the limit only after 14 days $(\Delta \mathrm{E} \mathrm{L}=$ $4.975 \pm 1.027$ and $\Delta \mathrm{E} \mathrm{E}=3.570 \pm 1.805)$. The color change of the composite resin in the coffee was found to be greater than that of the $\mathrm{L}$ and $\mathrm{E}$. Lauvahutanon et al. ${ }^{39}$ examined the color changes of four composite resin materials containing Filtek Supreme Ultra and eight CAD/CAM blocks containing Vita Enamic and Lava Ultimate in coffee and water over 1-day, 1-week, and 1-month periods. According to the results of this study, while the $\Delta \mathrm{E}$ values did not change significantly after immersion in water, they increased when specimens were immersed in coffee. Similar to the results of this study, the $\Delta \mathrm{E}$ values of conventional direct composite resins (Filtek Supreme Ultra and Durafill VS) were found to be significantly higher. In another study, Alharbi et al..$^{40}$ reported that a methacrylate-based direct composite Filtek Supreme showed the highest discoloration against UDMA-based and silorane-based composite resins and $\mathrm{CAD} / \mathrm{CAM}$ blocks. According to the findings of this study, a methacrylate-based direct Filtek Ultimate composite showed the highest discoloration against $\mathrm{L}$ and $\mathrm{E}$. Acar et al. ${ }^{41}$ reported that a methacrylate-based nanocomposite (Filtek Supreme Plus) showed the highest discoloration against a hybrid ceramic CAD/CAM block (Vita Enamic) and lithium disilicate glass ceramic (IPS e.max CAD). Severe 
discoloration of the direct composite resin materials is related to water absorption, and this was reported previously in the literature. ${ }^{39,42,43}$ Furthermore, the resin content of CAD/ CAM blocks with an improved degree of conversion causes better mechanical properties and resistance to discoloration. ${ }^{34,40,44}$

Dental ceramics are more resistant to discoloration than composite resin materials are. ${ }^{45,46}$ This can explain the finding that $\mathrm{L}$ showed more discoloration than $\mathrm{E}$ at the end of 28 days of immersion in coffee; E contains more ceramics, and thus, it is more resistant to coloration. It should be noted that discoloration is also related to the immersion medium. ${ }^{39,45}$ Poor oral hygiene of the individual and frequent consumption of coloring foods may cause color discrepancies between the CAD/CAM material and the repair composite later. However, this may not be a problem for someone who has good oral hygiene and does not consume coloring foods frequently. This must be considered when repairing the CAD/CAM blocks with composite resin materials.

\section{CONCLUSION}

Within the limitations of this study, the following conclusions were obtained: both the resin nanoceramic $(\mathrm{L})$ and hybrid (E) CAD/CAM blocks can be repaired with composite resins after proper surface treatments. The repair capacities of resin nanoceramic and hybrid CAD/CAM blocks before and after 10,000 thermal cycles were found to be similar. An additional silane application is recommended even when a silane-containing adhesive system is used for repairing $\mathrm{E}$ and L. Surface roughening with ErCr:YSGG lasers used with $3 \mathrm{~W}$ and $20 \mathrm{~Hz}$ parameters can be employed as an alternative method to coarse bur grinding for repairing $\mathrm{E}$ and L. It is likely that there will be a color difference between the CAD/CAM block and the repair composite after a certain time period.

\section{ORCID}

Hasibe Sevilay Bahadir https://orcid.org/0000-0001-8577-4408 Yusuf Bayraktar https://orcid.org/0000-0001-6250-5651

\section{REFERENCES}

1. Azeem RA, Sureshbabu NM. Clinical performance of direct versus indirect composite restorations in posterior teeth: A systematic review. J Conserv Dent 2018;21:2-9.

2. Alshehri SA. An investigation into the role of core porcelain thickness and lamination in determining the flexural strength of In-Ceram dental materials. J Prosthodont 2011;20:261-6.

3. Mörmann WH, Stawarczyk B, Ender A, Sener B, Attin T, Mehl A. Wear characteristics of current aesthetic dental restorative CAD/CAM materials: two-body wear, gloss retention, roughness and Martens hardness. J Mech Behav Biomed Mater 2013;20:113-25.

4. Zimmermann M, Valcanaia A, Neiva G, Mehl A, Fasbinder D.
Three-dimensional digital evaluation of the fit of endocrowns fabricated from different CAD/CAM materials. J Prosthodont 2019;28:e504-9.

5. Coldea A, Swain MV, Thiel N. Mechanical properties of polymer-infiltrated-ceramic-network materials. Dent Mater 2013; 29:419-26.

6. Awada A, Nathanson D. Mechanical properties of resin-ceramic CAD/CAM restorative materials. J Prosthet Dent 2015;114:587-93.

7. Lauvahutanon S, Takahashi H, Shiozawa M, Iwasaki N, Asakawa Y, Oki M, Finger WJ, Arksornnukit M. Mechanical properties of composite resin blocks for CAD/CAM. Dent Mater J 2014;33:705-10.

8. Della Bona A, Corazza PH, Zhang Y. Characterization of a polymer-infiltrated ceramic-network material. Dent Mater 2014;30:564-9.

9. Gracis S, Thompson VP, Ferencz JL, Silva NR, Bonfante EA. A new classification system for all-ceramic and ceramic-like restorative materials. Int J Prosthodont 2015;28:227-35.

10. FDI World Dental Federation. Repair of restorations: Adopted by the General Assembly: September 2019, San Francisco, United States of America. Int Dent J 2020;70:7-8.

11. Reston EG, Filho SC, Arossi G, Cogo RB, Rocha CS, Closs LQ. Repairing ceramic restorations: final solution or alternative procedure? Oper Dent 2008;33:461-6.

12. Güngör MB, Nemli SK, Bal BT, Ünver S, Doğan A. Effect of surface treatments on shear bond strength of resin composite bonded to CAD/CAM resin-ceramic hybrid materials. J Adv Prosthodont 2016;8:259-66.

13. Blum IR, Nikolinakos N, Lynch CD, Wilson NH, Millar BJ, Jagger DC. An in vitro comparison of four intra-oral ceramic repair systems. J Dent 2012;40:906-12.

14. Stawarczyk B, Krawczuk A, Ilie N. Tensile bond strength of resin composite repair in vitro using different surface preparation conditionings to an aged CAD/CAM resin nanoceramic. Clin Oral Investig 2015;19:299-308.

15. Kimyai S, Oskoee SS, Mohammadi N, Rikhtegaran S, Bahari M, Oskoee PA, Vahedpour H. Effect of different mechanical and chemical surface treatments on the repaired bond strength of an indirect composite resin. Lasers Med Sci 2015; 30:653-9.

16. Ozcan M, Barbosa SH, Melo RM, Galhano GA, Bottino MA. Effect of surface conditioning methods on the microtensile bond strength of resin composite to composite after aging conditions. Dent Mater 2007;23:1276-82.

17. Ghavami-Lahiji M, Firouzmanesh M, Bagheri H, Jafarzadeh Kashi TS, Razazpour F, Behroozibakhsh M. The effect of thermocycling on the degree of conversion and mechanical properties of a microhybrid dental resin composite. Restor Dent Endod 2018;43:e26.

18. Gale MS, Darvell BW. Thermal cycling procedures for laboratory testing of dental restorations. J Dent 1999;27:89-99.

19. Rinastiti M, Özcan M, Siswomihardjo W, Busscher HJ. Effects of surface conditioning on repair bond strengths of nonaged and aged microhybrid, nanohybrid, and nanofilled composite resins. Clin Oral Investig 2011;15:625-33.

20. Wendler M, Belli R, Panzer R, Skibbe D, Petschelt A, 
Lohbauer U. Repair bond strength of aged resin composite after different surface and bonding treatments. Materials (Basel) 2016;9. pii: E547.

21. Ataol AS, Ergun G. Effects of surface treatments on repair bond strength of a new CAD/CAM ZLS glass ceramic and two different types of CAD/CAM ceramics. J Oral Sci 2018; 60:201-11.

22. Mokhtarpour F, Alaghehmand H, Khafri S. Effect of hydrofluoric acid surface treatments on micro-shear bond strength of CAD/CAM ceramics. Electron Physician. 2017;9:5487-93.

23. Barutcigil K, Barutcigil C, Kul E, Ozarslan MM, Buyukkaplan US. Effect of different surface treatments on bond strength of resin cement to a CAD/CAM restorative material. J Prosthodont. 2019;28:71-8.

24. Kirmali O, Kapdan A, Harorli OT, Barutcugil C, Ozarslan MM. Efficacy of ceramic repair material on the bond strength of composite resin to zirconia ceramic. Acta Odontol Scand 2015;73:28-32.

25. Shiu P, De Souza-Zaroni WC, Eduardo Cde P, Youssef MN. Effect of feldspathic ceramic surface treatments on bond strength to resin cement. Photomed Laser Surg 2007;25:2916.

26. Kara HB, Dilber E, Koc O, Ozturk AN, Bulbul M. Effect of different surface treatments on roughness of IPS Empress 2 ceramic. Lasers Med Sci 2012;27:267-72.

27. Kursoglu P, Motro PF, Yurdaguven H. Shear bond strength of resin cement to an acid etched and a laser irradiated ceramic surface. J Adv Prosthodont 2013;5:98-103.

28. Subaş 1 MG, Alp G. Repair bond strengths of non-aged and aged resin nanoceramics. J Adv Prosthodont 2017;9:364-70.

29. Özel Bektas Ö, Eren D, Herguner Siso S, Akin GE. Effect of thermocycling on the bond strength of composite resin to bur and laser treated composite resin. Lasers Med Sci 2012; 27:723-8.

30. Demirtag Z, Culhaoglu AK. Surface roughness of ceramicresin composites after femtosecond laser irradiation, sandblasting or acid etching and their bond strength with and without silanization to a resin cement. Oper Dent 2019;44: 156-67.

31. Nihei T. Dental applications for silane coupling agents. J Oral Sci 2016;58:151-5.

32. Elsaka SE. Bond strength of novel CAD/CAM restorative materials to self-adhesive resin cement: the effect of surface treatments. J Adhes Dent 2014;16:531-40.

33. Yoshihara K, Nagaoka N, Sonoda A, Maruo Y, Makita Y, Okihara T, Irie M, Yoshida Y, Van Meerbeek B. Effectiveness and stability of silane coupling agent incorporated in 'universal' adhesives. Dent Mater 2016;32:1218-25.

34. Murillo-Gómez F, Rueggeberg FA, De Goes MF. Short- and long-term bond strength between resin cement and glass-ceramic using a silane-containing universal adhesive. Oper Dent 2017;42:514-25.

35. Sirisha K, Rambabu T, Ravishankar Y, Ravikumar P. Validity of bond strength tests: A critical review-Part II. J Conserv Dent 2014;17:420-6.

36. Armstrong S, Geraldeli S, Maia R, Raposo LH, Soares CJ, Yamagawa J. Adhesion to tooth structure: a critical review of "micro" bond strength test methods. Dent Mater 2010;26: e50-62.

37. Chaiyabutr Y, Kois JC, Lebeau D, Nunokawa G. Effect of abutment tooth color, cement color, and ceramic thickness on the resulting optical color of a CAD/CAM glass-ceramic lithium disilicate-reinforced crown. J Prosthet Dent 2011;105:8390.

38. Yilmaz B, Karaagaclioglu L. In vitro evaluation of color replication of metal ceramic specimens using visual and instrumental color determinations. J Prosthet Dent 2011;105:21-7.

39. Lauvahutanon S, Shiozawa M, Takahashi H, Iwasaki N, Oki M, Finger WJ, Arksornnukit M. Discoloration of various CAD/CAM blocks after immersion in coffee. Restor Dent Endod 2017;42:9-18.

40. Alharbi A, Ardu S, Bortolotto T, Krejci I. Stain susceptibility of composite and ceramic CAD/CAM blocks versus direct resin composites with different resinous matrices. Odontology 2017;105:162-9.

41. Acar O, Yilmaz B, Altintas SH, Chandrasekaran I, Johnston WM. Color stainability of CAD/CAM and nanocomposite resin materials. J Prosthet Dent 2016;115:71-5.

42. Shiozawa M, Takahashi H, Asakawa Y, Iwasaki N. Color stability of adhesive resin cements after immersion in coffee. Clin Oral Investig 2015;19:309-17.

43. Bagheri R, Burrow MF, Tyas M. Influence of food-simulating solutions and surface finish on susceptibility to staining of aesthetic restorative materials. J Dent 2005;33:389-98.

44. Nguyen JF, Migonney V, Ruse ND, Sadoun M. Properties of experimental urethane dimethacrylate-based dental resin composite blocks obtained via thermo-polymerization under high pressure. Dent Mater 2013;29:535-41.

45. Stawarczyk B, Sener B, Trottmann A, Roos M, Ozcan M, Hämmerle $\mathrm{CH}$. Discoloration of manually fabricated resins and industrially fabricated CAD/CAM blocks versus glass-ceramic: effect of storage media, duration, and subsequent polishing. Dent Mater J 2012;31:377-83.

46. Lange RT, Pfeiffer P. Clinical evaluation of ceramic inlays compared to composite restorations. Oper Dent 2009;34:26372. 